Article

\title{
Numerical Simulation for FSW Process at Welding Aluminium Alloy AA6082-T6
}

\author{
Nikola Sibalic * and Milan Vukcevic \\ Faculty of Mechanical Engineering, University of Montenegro, st. Dzordza Vasingtona bb, \\ 81000 Podgorica, Montenegro \\ * Correspondence: nikola@ucg.ac.me; Tel.: +382-20242917
}

Received: 5 June 2019; Accepted: 24 June 2019; Published: 3 July 2019

check for updates

\begin{abstract}
This paper presents the numerical simulation of the Friction stir welding (FSW) process obtained by using the DEFORM 3D software package. Numerical simulations are based on experimental research, welding of aluminum alloy AA6082-T6 by FSW method, which has the thickness of $7.8 \mathrm{~mm}$. The aim of this paper is to determine the reliability of numerical simulations in the FSW process, which is followed by large deformations, where influential geometric and kinematic parameters are varied. Numerical research was done on the basis of the adopted five-phase orthogonal experimental plan with a variety of factors on two levels and repetition at the central point of the plan for four times. The parameters varied in the experiment are: Welding speed $v \mathrm{~mm} / \mathrm{min}$, a rotation speed of tool $\omega \mathrm{rpm}$, angle of pin slopes $\alpha^{\circ}$, a diameter of the pin $d \mathrm{~mm}$, diameter of the shoulder $D \mathrm{~mm}$. During the performing of the FSW process, forces were measured in three normal directions: Axial force $F_{z}$, longitudinal force $F_{x}$ and side force $F_{y}$, as well as the temperature in the adopted measuring positions of the workpiece. The experimental results obtained in this way were compared with the numerical experiment in the same adopted measuring positions, i.e., in the paper an analysis and comparison of the obtained experimental and numerical data of the measured forces and the generated temperature field were made.
\end{abstract}

Keywords: FSW method; numerical simulations; welding force; temperature

\section{Introduction}

Friction stir welding is one of the most energy efficient processes and as such today has a great industrial application. It is used in all branches of industry, and primarily in space, aviation, shipbuilding, and rail industry. It features characteristics of an extremely good welded joint, the possibility of welding the plates of larger thicknesses, and the most important feature is the welding of dissimilar materials. Friction stir welding (FSW) was invented at the Welding Institute (TWI) of the United Kingdom in 1991 as a solid-state joining technique and was initially applied to aluminum-alloys [1-5]. The process is carried out by using a tool of a cylindrical shape. The tool consists of two concentric parts of different diameters. A part of the tool of the larger diameter is called the shoulder, while a smaller diameter part is called a pin and is cone-shaped [1-5]. The tool rotates at a high speed. The process FSW can be divided into two phases (Figure 1). In the first phase, the tool moves axially and plunges into the material. During this, the heat from the friction is generated between workpieces and the surface of the tool pin and due to the plastic deformation of the material. When the shoulder reaches the surface of the workpiece and the tool begins to move longitudinally, the second phase, or phase of the welding of the material, begins [5]. During this phase, in addition to the previously mentioned heat sources, most of the heat is obtained due to shoulder friction on the surface of workpieces [5]. Thus, on the heat generation, the greatest influence has geometric parameters of the tool (shoulder diameter, pin diameter, and angle of pin slopes), which define the quality of the 
welded joint with the kinematic parameters (welding speed and rotation speed of tool). Therefore, these most influential parameters are the subject of our research.

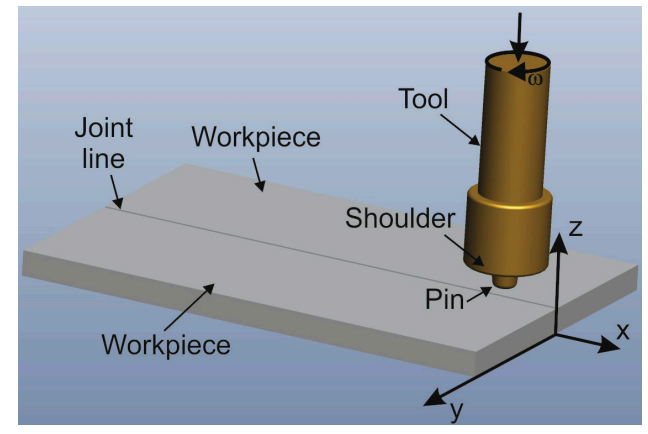

(a)

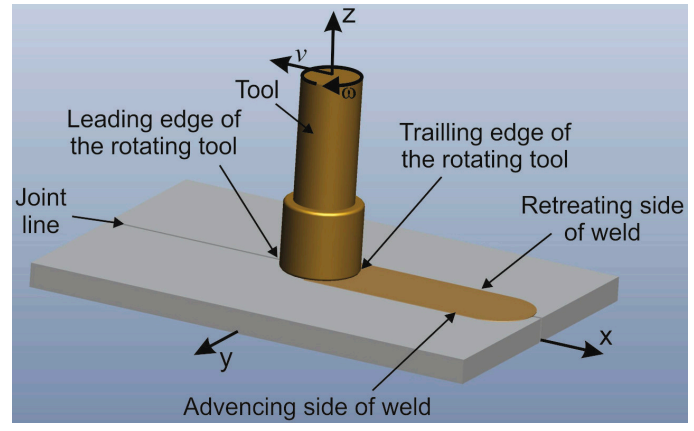

(b)

Figure 1. Performing the process Friction stir welding. (a) the first phase; (b) the second phase.

As experimental research from real material is expensive, numerical experiments through the use of various software packages have shown that data obtained very successfully describes the studied process. Therefore, in a large number of published papers, numerical simulations of the FSW process are performed.

The paper [6] deals with thermo-mechanical modeling and force analysis in the FSW process using the finite element method. When welding the sheet which is fixed in the rotating longitudinal movement of the tool using a mechanical force that is broken in three directions and combined with a temperature impact, deformation is caused and a solid welded joint is made. The natural assumption is that force control in FSW technology is important from the economic point of view, the aspect of productivity and the quality of welding. In order to design the FSW methodology, it is necessary to know the mechanical force, the speed of tool rotation, the longitudinal speed, the depth of the penetration of the tool into the material, and the thermo-mechanical properties of the material. This paper presents a three-dimensional model that is based on the method of finite elements for the distribution of temperature and stresses, taking into account the mechanical effects of the tool. Accordingly, a study of axial, longitudinal, and side forces is presented here in the process of welding aluminum alloy 6061 . The welding process is simulated using a commercial package of finite elements ANSYS.

The paper [7] presents an attempt to model the FSW process using a three-dimensional visco-plastic model. The field of this paper is focused on joining a thick aluminum sheet. The numerical model represents the successful design of the welding tools, which will produce the desired thermal gradient and prevent the breaking of the tools. Simulation of the welding process FSW with the finite element method was done using commercial FIDAP software (v7.6, Evanston, IL, USA).

The FSW method [8] with stainless steel procedure was modeled using Euler's formulation. Coupled high-viscous flow and a heat transfer of tool's pin are considered. Model equations were solved using the finite element method in determining the speed and field of temperature distribution.

In the paper [9], a two-dimensional simulation of the FSW process was performed, using finite elements and different ABAQUS options. The FSW process simulation focuses on the area of speed and characteristics of material flow.

When it comes to modeling the FSW process, great efforts are being made to understand the physical basis of the process through the study of experimental research.

The most commonly used software in modeling and numerical simulations in FSW friction welding processes are: ANSYS [6], FIDAP [7], ABAQUS [9-11], MATLAB [12], STIR3D [13], and DEFORM $[14,15]$. 
The paper [15] refers to the modeling of the FSW process, by using a commercially available nonlinear finite element (FE) code DEFORM. Temperature distribution, residual stress, strain and strain rates were analyzed in different regions of the welded joint.

Numerical modeling of FSW takes into account the thermal history [7,15-18], the microstructure [12], and the flow of materials [7,17-19]. Different numerical modeling approaches, such as finite elements $[7,10,16,17]$ or final differences $[12,20]$, have been used. These models were applied in determining the significance of the transmission effects, the prediction of local deformations [12], simulating the appearance of the dissolution of the sediment along the grain boundaries [20], determining the dependence of material viscosity on the temperature and process parameters [19], calculating the pressure and velocity and connection of the process parameters with temperature and force on the tool [7]. A certain group of materials has been taken into consideration, such as AA7050-T7451 [7], AA2195-T8 [10], AA6082.05-T6 and AA7108.50-T79 [12], Ti-6Al-4V and AA1100 [15], AA5454-O [18], and AA6061-T6 [19].

In the paper [3], the influence of the tool's angle of pin slope on the generated heat and material flow is researched. The effect of the tilt angle on the FSWelds is modeled through the contact condition by modifying an enhanced friction model. The mechanical effects caused by the tool tilt angle are presented in terms of velocity, stresses and strain rate fields, and material flow around the tool.

In the paper [4], welding of dissimilar materials 2017A-T451 and 7075-T651 was performed. An existing computational model of the welding process for temperature distribution and material flow was adapted to estimate the phase transformations that occur in the weld zone. The phase transformation maps predicted by the simulation correlate with the hardness profiles and positron lifetime curves taken over the weld zone from the weld center (nugget) through the TMAZ to the HAZ.

The paper [21] deals with the research of the metallurgical and microstructural aspects of FSW in terms of grain size and microhardness. The modeling is based on a combination of an apropos kinematic framework for local simulation of FSW processes and a material particle tracing technique for tracking the material flow during the weld. The resulting grain size and microhardness values are validated with experimental observations from an identical processed sample.

One of the most commonly used programs for volume deformation processes is the DEFORM package with multiple modules. DEFORM is based on the finite element method (FEM). For the numerical simulations in this research, the DEFORM 3D module was used.

\section{Experimental Research}

The machine used for the FSW process is a universal milling machine (6P13, GZFS, Russia), of a large stiffness. The milling machine has a movable working table of size $1500 \mathrm{~mm} \times 300 \mathrm{~mm}$, with the possibility of adjusting the stroke speed $(\mathrm{mm} / \mathrm{min})$, as well as the speed of the main spindle (rpm). The weight of the machine is $3500 \mathrm{~kg}$ and the motor power is $10 \mathrm{~kW}$.

The material used in the experimental research is aluminum alloys AA6082-T6 with the thickness of $7.8 \mathrm{~mm}$. This alloy has a great industrial application due to its good mechanical properties and relatively light weldability. For the experiment purposes, workpieces of $200 \mathrm{~mm} \times 50 \mathrm{~mm} \times 7.8 \mathrm{~mm}$ were made. For the welding process, the simple geometric shape tool is given in Figure 2. The FSW process is achieved at a constant welding speed [22].

For experimental research, the experiment plan was adopted and the input factors on the basis of which the output sizes were monitored. For the experiment plan, a complete five-factor orthogonal plan was adopted with a variety of factors on two levels and repetition at the central point of the plan $n_{0}=4$. The total number of experimental points is determined by the expression:

$$
N=2^{k}+n_{0}
$$




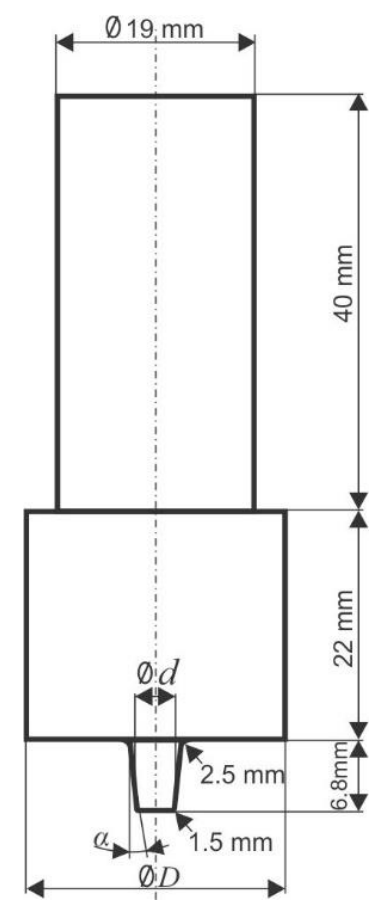

Figure 2. The used tool for the FSW process.

According to Equation (1), the number of experimental points is $N=36$, for the number of factors $k=5$. In order to determine the output size $(Y)$, the boundaries of the variation interval must be adopted so that the condition is satisfied:

$$
X_{b i}^{2}=X_{u i} \cdot X_{l i}, i=1, \ldots, 5
$$

where is:

$X_{u i}$-the value of the $i$-th factor at the upper level,

$X_{l i}$-the value of the $i$-th factor at the lower level,

$X_{b i}$ - the value of the $i$-th factor at the basic level.

This condition applies to orthogonal plans. The $i$-th factor levels are encoded by the transformation equation:

$$
x_{i}=\frac{X_{i}-X_{b i}}{w_{i}}, i=1, \ldots, 5
$$

where they are:

$X_{i}$ - the natural value of the $i$-th factor and,

$w_{i}$-the factor variation $X_{i}$ interval whose numerical value is equal to the difference between the upper and the basic levels, ie the base and lower levels.

Geometric and kinematic parameters are applied as input quantities:

$X_{1}=v \mathrm{~mm} / \mathrm{min}$-welding speed,

$X_{2}=\omega \mathrm{rpm}$-rotation speed of tool,

$X_{3}=\alpha^{0}$-the angle of pin slope,

$X_{4}=d \mathrm{~mm}$-tool pin diameter,

$X_{5}=D \mathrm{~mm}$-tool shoulder diameter.

Taking into account Equation (2), the adopted levels of input factor variation are given in Table 1. 
Table 1. Levels of variation of input factors.

\begin{tabular}{ccccccc}
\hline No. & $\begin{array}{c}\text { Welding Speed } \\
\text { mm/min }\end{array}$ & $\begin{array}{c}\text { Rotation Speed } \\
\text { of Tool } \\
\text { rpm }\end{array}$ & $\begin{array}{c}\text { The Angle of } \\
\text { Pin Slope } \\
\circ\end{array}$ & $\begin{array}{c}\text { Tool Pin } \\
\text { Diameter } \\
\text { mm }\end{array}$ & $\begin{array}{c}\text { Tool Shoulder } \\
\text { Diameter } \\
\text { mm }\end{array}$ & $\begin{array}{c}\text { Output } \\
\text { Vectors } Y\end{array}$ \\
\hline & $X_{1}=v$ & $X_{2}=\omega$ & $X_{3}=\alpha$ & $X_{4}=d$ & $X_{5}=D$ & $\mathrm{~F}_{x}, \mathrm{~F}_{\mathrm{y}}, \mathrm{F}_{\mathrm{z}}$ \\
$x_{u i}$ & 200 & 1000 & 5 & 7 & 28 & $T_{1}, T_{2}, T_{3}$ \\
$x_{l i}$ & 80 & 630 & 3 & 5 & 25 & $T_{4}, T_{5}, T_{6}$ \\
$x_{b i}$ & 125 & 800 & 3.87 & 5.92 & 26.46 & \\
\hline
\end{tabular}

For the research needs, a set of 9 tools which geometric values were varied according to the adopted experiment plan. Also, 72 workpieces were produced, which are joined by the FSW process in 36 experimental points. In Figure 3, the obtained welded compound is shown in experimental point number 1.

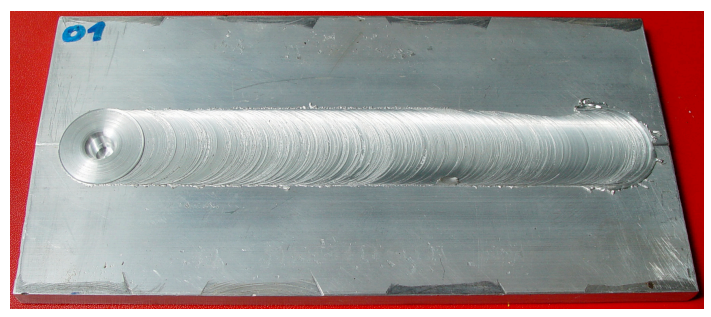

(a)

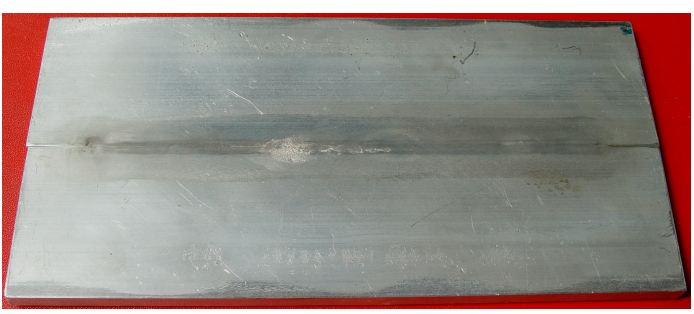

(b)

Figure 3. The welded joint in the 1st point of the experimental plan. (a) a view from the top; (b) a bottom view.

\subsection{Measurement of Forces}

Analog-digital equipment connected to the information measurement system was used to measure the force in three normal directions. The accessory on which the clamping of workpieces is carried out and the process of FSW is running is mounted on special carriers equipped with sensors, which are connected with the six channel amplifier (KWS 3073, HBM, Darmstadt, Germany), where the signal is transmitted to the $\mathrm{AD}$ card, and the data processed using software for data acquisition. The sensors used are the strain gauges that are connected in the full Wheatstone bridges, which change the electrical signal based on the elastic deformation of special carriers that are loaded with both bending and compression. All used strain gauges are of type: HBN 6/120LY11, resistance $120 \Omega \pm 0.2 \%$ and $k$ - factor $2.05 \pm 1 \%$. To measure the force components, it was necessary to separate the components of the force obtained by bending of the special carriers from those obtained by compression.

The force components measured during the process are the axial force $F_{z}$, the longitudinal force $F_{x}$, and the side force $F_{y}$ (Figure 4).

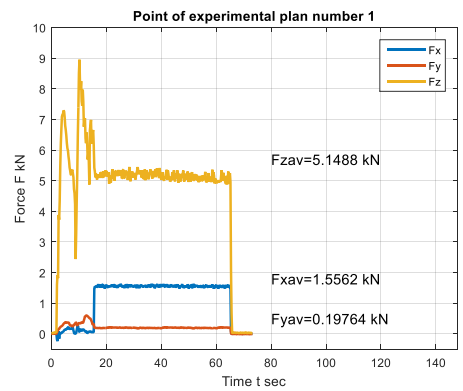

(a)

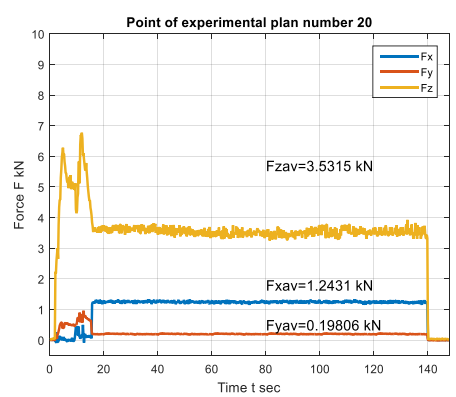

(b)

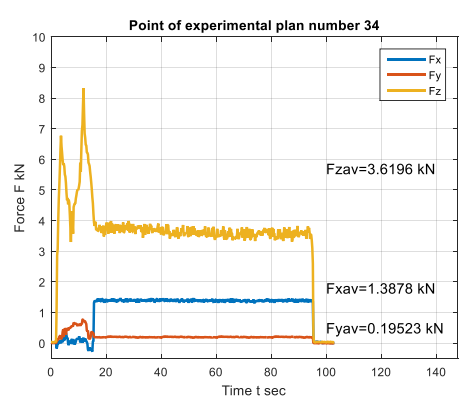

(c)

Figure 4. Diagram of forces $F_{z}, F_{x}$, and $F_{y}$ at the points of the experimental plan: (a) number 1; (b) umber 20; (c) number 34. 


\subsection{Temperature Measurement}

To measure the temperature, workpieces with mounted thermocouples made of Al-Cr wire are made. The adopted thermocouple installation scheme with respect to the joint line is given in Figure 5. Temperature measurement was adopted in 6 positions. Three are located in the upper zone, and three in the lower zone of welding. This adopted schedule allows us to measure the temperature in all microstructural zones. In Figure 6, diagrams of the measured temperature at the points 1, 20, and 34 of the experimental plan for the positions of thermocouples $T_{1}, T_{2}, T_{3}, T_{4}, T_{5}$, and $T_{6}$ in the function of time are shown [22].

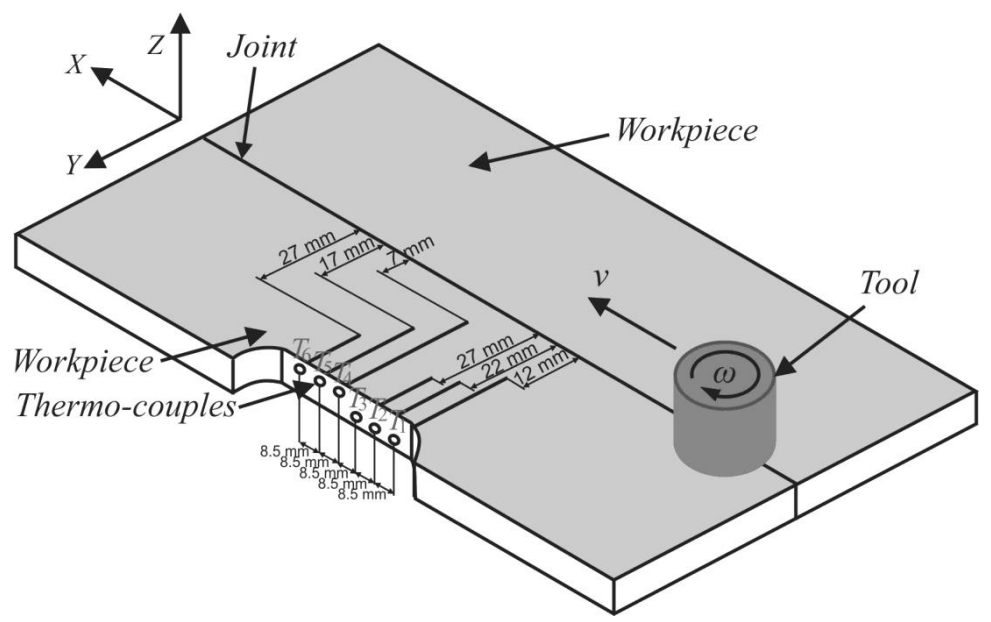

Figure 5. Scheme of measuring temperature positions in the workpiece to be welded [22].
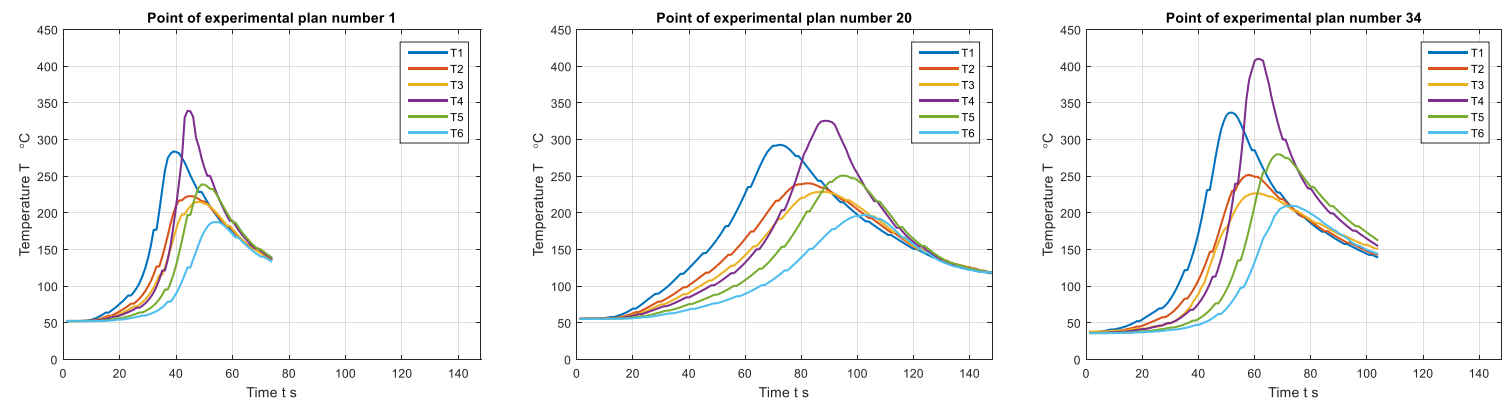

Figure 6. Diagram of temperature at the points of the experimental plan number: 1, 20, and 34 [22].

\section{Numerical Simulation}

Using the DEFORM3D (v5.0, SFTC, Columbus, OH, USA) software package, numerical simulations were performed. Tools and workpieces are generated in the CAD software CREO (v5.0, PTC, Boston, MA, USA). In order to be able to compare the obtained results with real conditions, 36 numerical simulations were performed based on the adopted experimental plan. Numerical simulation for each point of the experimental plan can be divided into two phases consisting of two stages (Figure 7). In the first phase, the pin tool moves axially and plunges into the material at a depth of $6.9 \mathrm{~mm}$ and a shoulder of the tool at $0.1 \mathrm{~mm}$, at a speed of $v=30 \mathrm{~mm} / \mathrm{min}$. In the second phase, the tool moves longitudinally $166 \mathrm{~mm}$, adopted at varying speeds $v_{u}=200 \mathrm{~mm} / \mathrm{min}, v_{l}=80 \mathrm{~mm} / \mathrm{min}$ and $v_{b}=125 \mathrm{~mm} / \mathrm{min}$.

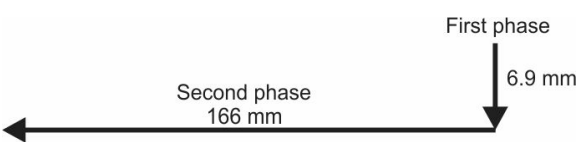

Figure 7. The scheme of the tool movement in the numerical simulations. 
The DEFORM-3D module contains data that corresponds to the value of the real experiment. In submodule Simulation Control, the data related to the choice of system units are entered, the number of simulation steps, step increment to save, as well as the values of the termination process - SMAX. In the submodule Material, the data related to the material of the workpiece are entered. The ALUMINIUM-6082 material is selected whose parameters are in the database of DEFORM-3D which is defined:

$$
\bar{\sigma}=\bar{\sigma}(\bar{\varepsilon}, \dot{\bar{\varepsilon}}, T)
$$

where: $\bar{\sigma}$ - flow stress, $\bar{\varepsilon}$ - effective plastic strain, $\dot{\bar{\varepsilon}}$ - effective strain rate, and $T$ - temperature.

In the submodule Mesh, the number of 40,000 elements is selected, which is generated on the workpieces, and the submodule Movement contains values of moving speed tools (welding speed) and angular velocity (rotation speed of tool). For the first phase in the submodule Movement, the tool speed $0.5 \mathrm{~mm} / \mathrm{sec}$ in the direction of " $-\mathrm{z}$ " (Constant) and in submodule Rotation 1 angular velocity $83.78 \mathrm{Rad} / \mathrm{sec}$ in the direction of " $\mathrm{z}$ " (Constant) are entered. In the second phase, the basic plate is the primary die and its speed corresponds to the point of the experimental plan, in this case, $2.0833 \mathrm{~mm} / \mathrm{sec}$ which corresponds to the speed of $125 \mathrm{~mm} / \mathrm{min}$. At this phase, the tool speed is $0 \mathrm{~mm} / \mathrm{sec}$, and the angular velocity $83.78 \mathrm{Rad} / \mathrm{sec}$, which corresponds to the rotation speed of the tool of $800 \mathrm{rpm}$ [22].

In the Inter-Object submodule (Table 2) data are given relating to the relationship between the mold and the workpiece, as well as the friction factor and the heat transfer coefficient.

Table 2. Inter-Object.

\begin{tabular}{ccc}
\hline Parameters & Tools9 - & Basic Plate - \\
& - Workpiece & - Workpiece \\
\hline Contact relation CNTACT & Master-Slave & Master-Slave \\
Friction model FRCFAC & Shear & Shear \\
Friction & 0.4 & 0.4 \\
Heat Transfer Coefficient & 5 & 5 \\
\hline
\end{tabular}

Other parameter values are taken as the default values of the software package DEFORM-3D. After entering the input data and generating the finite element mesh, the initial database for the initial step is formed, referred to as -1 . When a database is formed, then all necessary requirements are met in order to perform the simulation of the FSW process. After the simulation, the results can be interpreted in the module Post Processor in the data and graphical form. Figure 8 shows a 3D preview of workpieces with the generated finite element mesh [22].

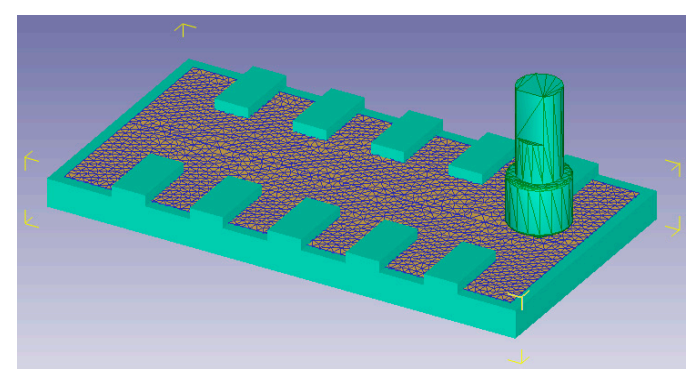

Figure 8. Workpieces with the generated mesh.

When the simulation starts the numerical calculations for the value of progressing step DSMAX $=0.1 \mathrm{~mm}$ are performed, which was previously adopted. Every tenth step is stored in the database. When the finite element mesh parameters reach critical values the automatic remeshing occurs. The process of the first phase ends with the 115-step. Forces $F_{z}, F_{x}$, and $F_{y}$ which occur during the first phase of the numerical simulations for the 34 th point of the experimental plan are presented in Figure 9. 


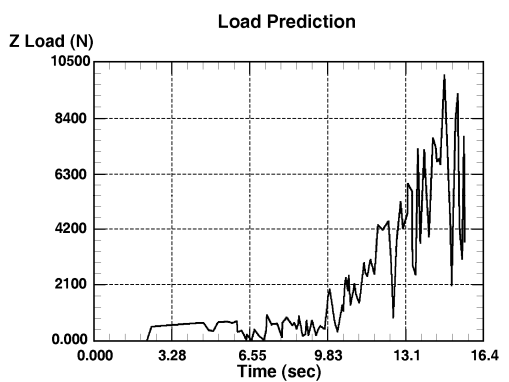

(a)

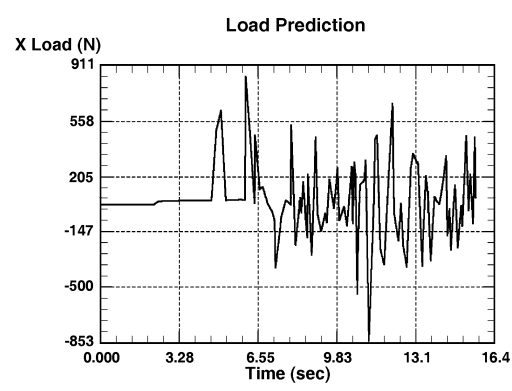

(b)

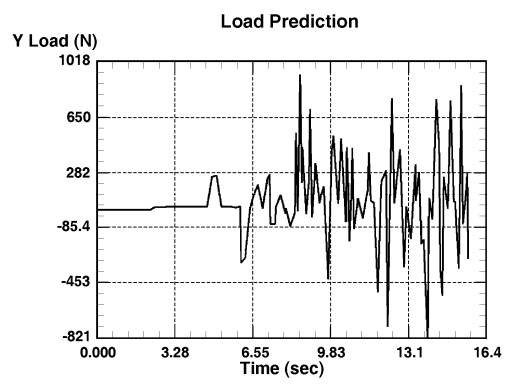

(c)

Figure 9. The forces obtained by numerical simulation in the first stage of the process for the 34th point of the experimental plan: (a) Axial force $F_{z} ;(\mathbf{b})$ longitudinal force $F_{x} ;(\mathbf{c})$ side force $F_{y}$.

After the commencement of the simulation for the second phase, numerical calculations of the progressing steps are carried out. At this phase, automatic remeshing also takes place. The process was completed in 1853rd step and thus the numerical simulation of FSW. Forces $F_{z}, F_{x}$, and $F_{y}$ of the second phase of simulation for the 34th point of the experimental plan are given in Figure 10. Data for welding force components obtained in DEFORM 3D, for all points of the experimental plan, are processed in the MATLAB (vR2015a, MathWorks, Natick, MA, USA) software, and for the points 1 and 20 of the experimental plan, shown in Figure 11.

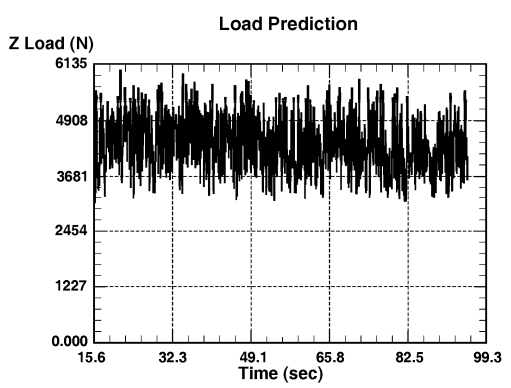

(a)

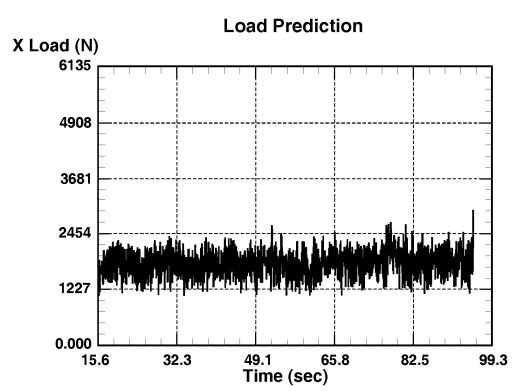

(b)

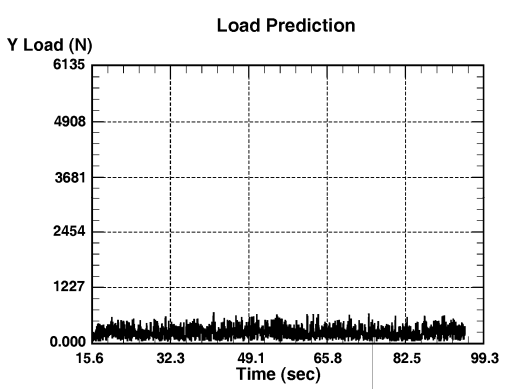

(c)

Figure 10. The forces obtained by numerical simulation in the second stage of the process for the 34th point of the experimental plan: (a) Axial force $F_{z} ;(\mathbf{b})$ longitudinal force $F_{x} ;(\mathbf{c})$ side force $F_{y}$.

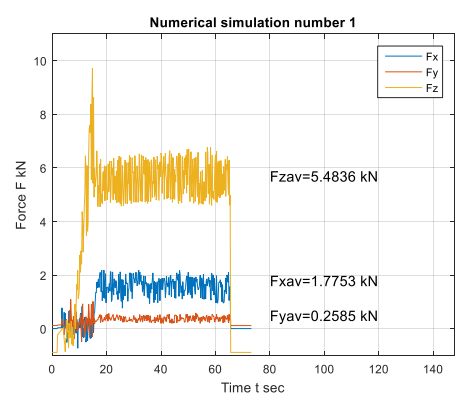

(a)

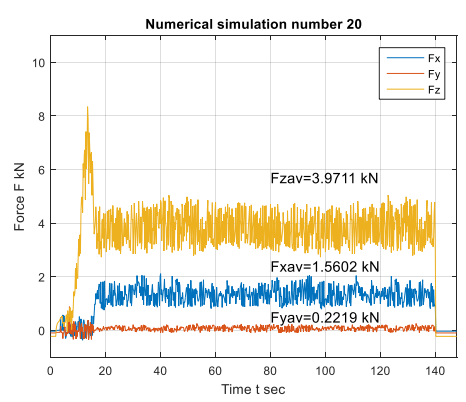

(b)

Figure 11. Forces obtained by numerical simulation (a) for the 1st point of the experimental plan; (b) for the 20th point of the experimental plan.

Also, the final distribution of temperature fields at the end of the first (115 steps) and the second phase (1853 step) of the FSW process for the 1st point of the experimental plan is shown in Figure 12. 


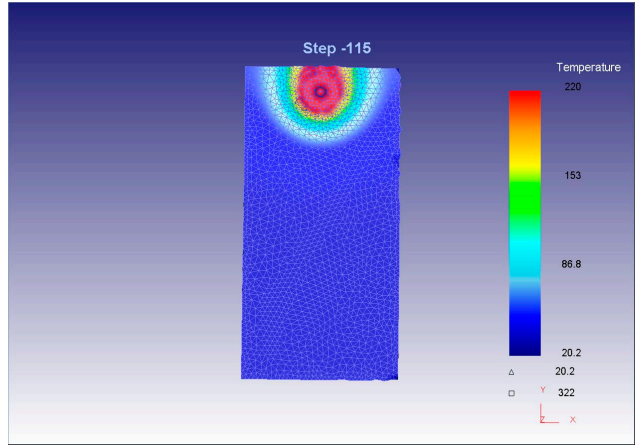

(a)

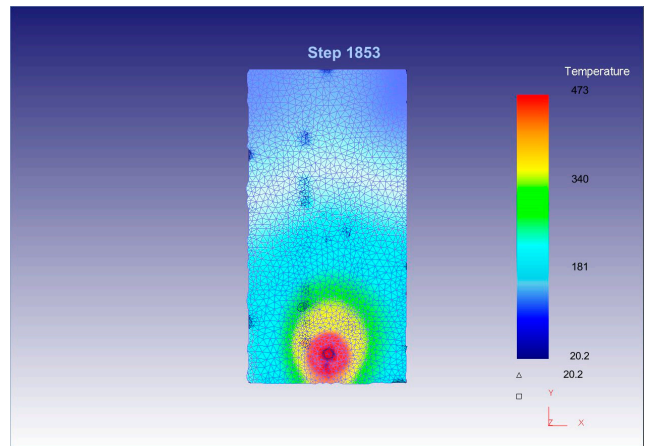

(b)

Figure 12. Distribution of temperature fields: (a) At the end of the first phase of the FSW process; (b) at the end of the second phase of the FSW process.

For the defined measurement positions of the workpiece temperature in the microstructural zones in the Point Tracking submodule, the results for the central points of the experimental plan are shown in Figure 13, while Table 3 shows the maximum values of the received temperature values in the adopted measuring points for 1 and 20 and 34 the point of the experimental plan [22].

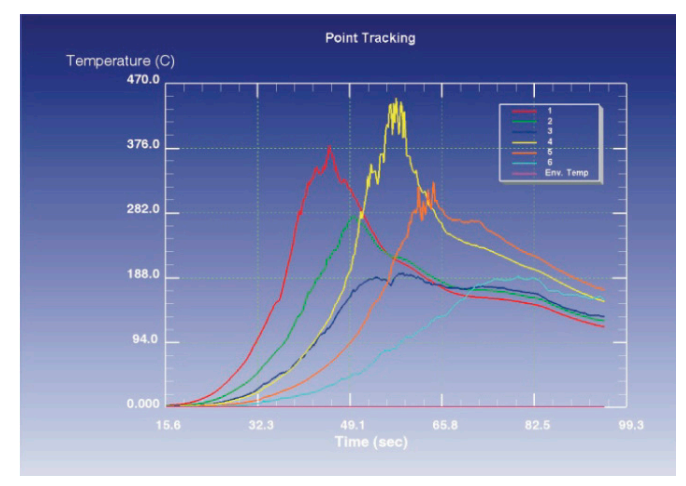

Figure 13. The resulting temperature diagram numerical simulations at the six selected points for 33rd, 34 th, $35^{\text {th }}$, and 36th point of the experimental plan [22].

Table 3. Point Tracking (Temperature ${ }^{\circ} \mathrm{C}$ ).

\begin{tabular}{ccccccc}
\hline No. & $\mathbf{1}$ & $\mathbf{2}$ & $\mathbf{3}$ & $\mathbf{4}$ & $\mathbf{5}$ & $\mathbf{6}$ \\
\hline 1. & 305.92 & 219.31 & 170.23 & 371.82 & 263.51 & 161.90 \\
20. & 313.46 & 243.85 & 193.96 & 358.62 & 281.47 & 187.19 \\
34. & 383.25 & 278.42 & 193.17 & 445.10 & 328.03 & 187.62 \\
\hline
\end{tabular}

\section{Results and Discussion}

During experimental research and numerical simulations, the diagrams of the force components, which occur during the welding process and the temperature diagrams in the adopted measuring positions, are obtained.

From Figure 4, it can be seen that the duration of the process depends on the welding speed. For the speed of $200 \mathrm{~mm} / \mathrm{min}$ (Figure 4a), the duration of the welding process is $49.8 \mathrm{~s}$. For a speed of $80 \mathrm{~mm} / \mathrm{min}$ (Figure $4 \mathrm{~b}$ ), the duration of the welding process is $124.5 \mathrm{~s}$. For the center points of the experimental plan and the speed of $125 \mathrm{~mm} / \mathrm{min}$ (Figure 4c), the duration of the welding process is $79.68 \mathrm{~s}$. The duration of the process is very important from the point of view of the quality of seams and the productivity of the welding process.

For all points of the experimental plan in the first stage of the process, the forces $F_{z}$ and $F_{y}$ reach their highest values. Since in this stage the tool is plunged into the material, variable values of the force 
are obtained. As $F_{z}$ is an axial force that presses material, it always has positive values. Due to the consequence of heat generation when plunging the tool, the $F_{x}$ force material may also have negative values ranging from -0.12 to $-0.48 \mathrm{kN}$ for all points of the experimental plan. As the direction of rotation of the tool corresponds to the direction of rotation of the hands on the clock, the values of force $F_{y}$ are obtained positively, because, during rotation, the tool tends to turn the workpieces in the same direction. At this stage, the maximum values of the force $F_{z}$ for all points of the experimental plan range from 5.3620 to $9.7300 \mathrm{kN}$, while the values of force $F_{y}$ range from 0.3877 to $1.1375 \mathrm{kN}$.

When the welding process begins, or the second phase, the forces $F_{x}, F_{y}$ and $F_{z}$ retain constant values. For the process of welding by FSW, from the point of view of energy consumption, the most important is the vertical component of the force $F_{z}$, which is often called the welding force. For each point of the experimental plan, the component $F_{z}$ compared to the other two components of the force $F_{x}$ and $F_{y}$ has a higher value. The force $F_{z}$ ranges from 2.4099 to $5.4799 \mathrm{kN}$, and the force $F_{x}$ from 1.0118 to $1.7561 \mathrm{kN}$, while the force $F_{y}$ is from 0.0987 to $0.2316 \mathrm{kN}$.

On the value of the $F_{x}$ force, the welding speed has the greatest influence. The higher the welding speed, the greater the resistance of the material to the tool, and the higher values of the longitudinal force $F_{x}$ are obtained. Another significant factor that influences the value of force $F_{x}$ is the angular rotation speed of the tool, and the third surface of the tool in contact with the material. If the rotation speed of tool is larger and the surface of the tool is larger, more heat is generated, so the tool moves easily through the material so that the resistance is smaller and the lower value of the $F_{x}$ force is obtained. If the rotation speed of tool is smaller, and the surface of the tool will generate less heat, so the resistance to the movement of the tool will be higher, and therefore the longitudinal force $F_{x}$ will be higher.

During the FSW process, the $F_{y}$ force acting in the side direction has relatively low values compared to other forces, so its influence on the welding process is relatively small.

In executed numerical simulations, the duration of the process is analogous to experimental.

For all numerical simulations in the first stage of the process, the forces $F_{z}$ and $F_{y}$ reach their highest values. Analogously to the experimental values in this stage, variable values of the force are obtained. For numerical simulations, the force $F_{z}$ always has positive values, while the forces $F_{x}$ and $F_{y}$ have negative values in this stage of plunging the tool into the material. Force $F_{x}$ and $F_{y}$ at this stage have approximate values that range within $\pm 1.2 \mathrm{kN}$. At this stage, the maximum values of the force $F_{z}$ for all numerical simulations range from 7.1982 to $11.5214 \mathrm{kN}$.

In the second phase of the process, the forces $F_{x}, F_{y}$ and $F_{z}$ also retain constant values until the simulation is complete, after $166 \mathrm{~mm}$ of travel. In each numerical simulation, the component $F_{z}$ has higher values than the components $F_{x}$ and $F_{y}$. Force $F_{z}$ in this stage for all numerical simulations ranges from 3.3429 to $6.3681 \mathrm{kN}$, and force $F_{x}$ from 1.2968 to $2.2801 \mathrm{kN}$, while force $F_{y}$ is from 0.1420 to $0.3103 \mathrm{kN}$. For numerical simulations of the FSW process, the force $F_{y}$, which acts in the side direction, also has relatively small values, so its effect on the friction welding process is small.

In Figure 14, the values of the most influential axial force $F_{z}$, that is, the welding forces obtained by experimental and numerical simulations, are given.

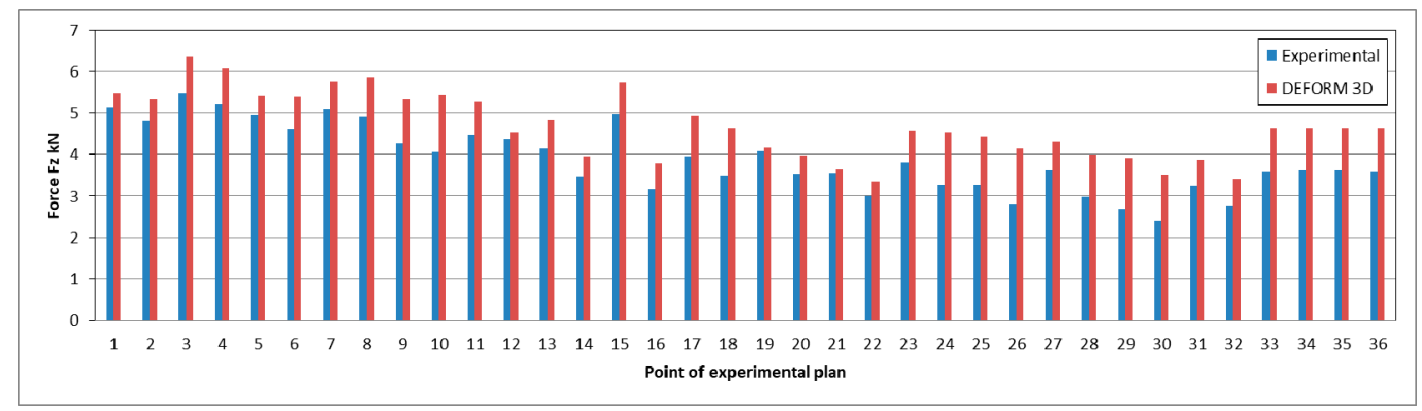

Figure 14. The obtained values of the welding force $F_{z}$ for all points of the experimental plan. 
For the analysis of the temperature variation in relation to the variable parameters of experimental research, in Figure 15, the maximum values of the temperatures measured using thermocouples $T_{1}, T_{2}$, $T_{3}, T_{4}, T_{5}$, and $T_{6}$ for all points of the experimental plan are shown.

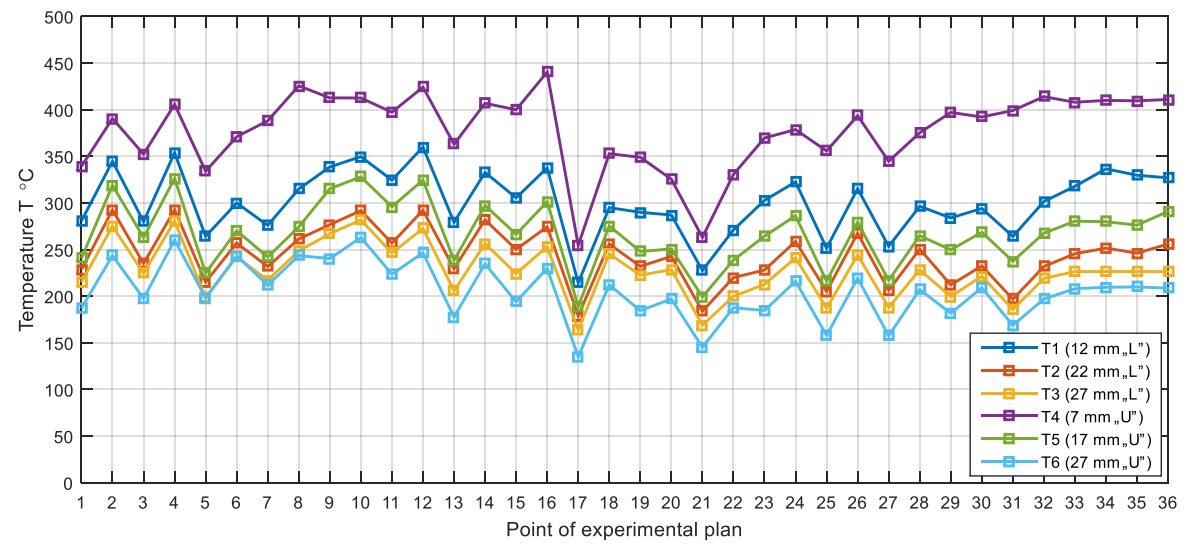

Figure 15. The obtained values of the welding temperature in the adopted measuring positions, for all points of the experimental plan.

The largest measured value of the temperature is at the 16th point of the experimental plan and is $440.4{ }^{\circ} \mathrm{C}$. As the temperature of melted aluminum alloys $6080-\mathrm{T} 6,555^{\circ} \mathrm{C}$, it can be noted that the FSW process is performed for all points of the experimental plan in the solid state without the melting effect of the material that characterizes the conventional welding processes. Since temperature is measured at certain distances from the joint line, obtained results can be analyzed. The thermocouple closest to the source of heat is $T_{4}$. This thermocouple is at a distance from the joint line of $7 \mathrm{~mm}$, so at this measuring point, the highest values of the measured temperature are obtained. The smallest measured value in the thermocouple number $T_{4}$ is at the 17 th point of the experimental plan and is $254.5^{\circ} \mathrm{C}$. Otherwise, in the 17 th point of the experimental plan, the least measured values for all other thermocouple positions were obtained, and the smallest was $135.1^{\circ} \mathrm{C}$, at a distance of $27 \mathrm{~mm}$ from the joint line in the upper zone. The reason for this low value of the temperature obtained is the consequence of the unfavorable relationship of the varied factors, which resulted in poor quality seams.

At a distance of $12 \mathrm{~mm}$ from the joint line in the lower zone, the highest temperature value in the 12 th point of the experimental plan is measured and it is $360^{\circ} \mathrm{C}$. At the 10 th point of the experimental plan, at a distance of $17 \mathrm{~mm}$ from the joint line in the upper zone, the maximum temperature value was measured and it is $328^{\circ} \mathrm{C}$. At this point, the maximum value of the temperature was measured at a distance of $27 \mathrm{~mm}$ in the lower zone $281.8^{\circ} \mathrm{C}$ and in the upper zone $263^{\circ} \mathrm{C}$. At the 4 th point of the experimental plan at a distance of $22 \mathrm{~mm}$ from the joint line in the lower zone, the highest temperature value was measured at $292.7^{\circ} \mathrm{C}$.

In Figure 16, a diagram of the maximum received temperature is given in the selected six measurement positions of Point Tracking submodules obtained in the DEFORM 3D software, which are processed in MATLAB, for all numerical simulations performed.

Since point $P_{4}$ is closest to the joint line, at this point we have the highest values of the numerically generated temperature. The lowest value of the temperature at point $P_{4}$ is in the 21st simulation and is $310.14^{\circ} \mathrm{C}$. At point $P_{1}$ located in the lower zone and $12 \mathrm{~mm}$ from the joint line, the highest temperature value was obtained also in the 16 th simulation, which is $405.04{ }^{\circ} \mathrm{C}$. In the 17 th simulation for the points $P_{1}, P_{2}, P_{3}, P_{5}$, and $P_{6}$, the lowest temperature values were obtained, and the smallest is at the point $P_{3}$ of the upper zone, at a distance of $27 \mathrm{~mm}$ from the joint line and is $112.30{ }^{\circ} \mathrm{C}$. Point $P_{5}$ is located in the upper zone at a distance of $17 \mathrm{~mm}$ from the joint line, and the highest temperature was measured in the 12 th numerical simulation and is $354.15^{\circ} \mathrm{C}$. In the 12 th simulation at point $P_{2}$, located in the lower zone at a distance of $22 \mathrm{~mm}$ from the joint line, the highest temperature value was obtained, which is 
$310.26^{\circ} \mathrm{C}$. In the 10th simulation, at points $P_{3}$ and $P_{6}$, the highest temperature was obtained. For point $P_{3}$ it is $233.26^{\circ} \mathrm{C}$, and for $P_{6}, 227.70^{\circ} \mathrm{C}$.

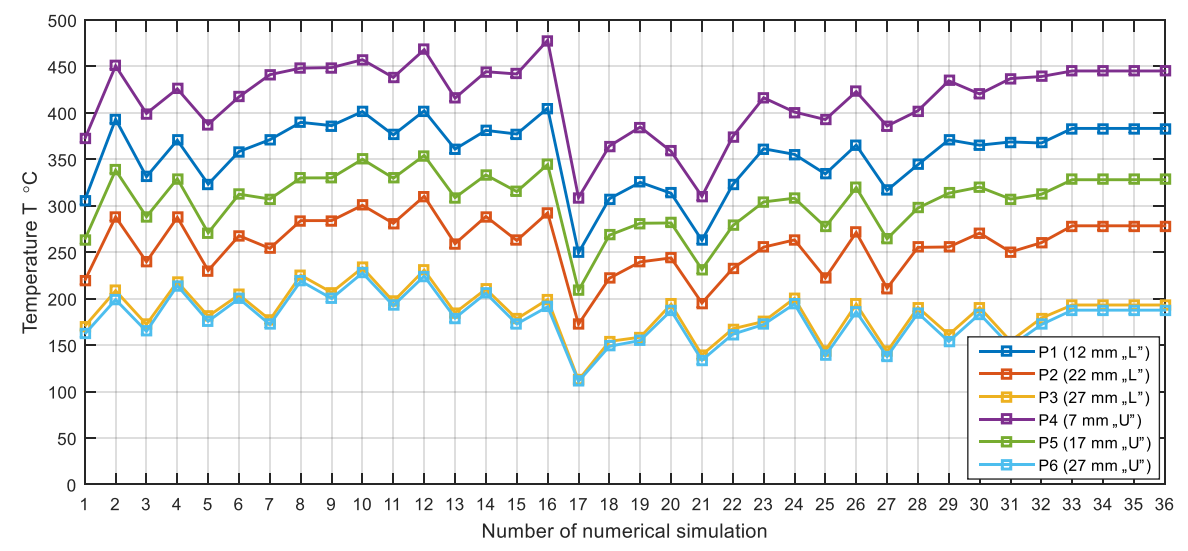

Figure 16. The obtained welding temperature values for all numerical simulations.

\section{Conclusions}

In this paper, the force components $F_{x}, F_{y}$ and $F_{z}$ were determined, as well as the distribution of the welded sample temperature from the aluminum alloy obtained by the FSW method. The influence of tool geometry (diameter of the shoulder, pin diameter, and angle of pin slope) and the welding speed and rotation speed on the change of force and temperature were investigated. The experiments were performed experimentally using special tools and accessories, as well as numerically, using the DEFORM 3D software package. By analyzing the obtained dependencies, we conclude that the FSW technology can be successfully applied to the welding of the investigated alumina alloy AA6082-T6.

A special contribution of the paper is the comparison of experimental and numerical results in the case of simultaneous changes in geometric and kinematic parameters, which is enabled by the adopted experimental plan.

For the FSW welding process from the investigated components of the force, the most important is the axial component $F_{z}$, which is often called the welding force. It can be concluded that the geometric parameters of the tool, especially the size of the shoulder of the tool, have the largest influence on the $F_{z}$ value. All obtained values of the $F_{z}$ force can be divided into three areas. The first 16 points of the experimental plan belong to the first area. This is the area where the diameter of the shoulder of the tool is $28 \mathrm{~mm}$. Here the values of the force $F_{z}$ are obtained from the limits of 3.4614 to $5.4799 \mathrm{kN}$. The other area belongs to the points of the experimental plan from 17 to 32, where the diameter of the shoulder of the tool is $25 \mathrm{~mm}$, and the force ranges from 2.4099 to $4.0428 \mathrm{kN}$. The third area belongs to the central points of the plan, where the diameter of the shoulder of the tool is $26.46 \mathrm{~mm}$, and the mean value of the force $F_{z}$ at these points is $3.6008 \mathrm{kN}$.

In numerical simulations, all the obtained values of the force $F_{z}$ can also be divided into three areas: The area of the larger diameter of the shoulder of the tool of $28 \mathrm{~mm}$, the area of the smaller diameter of the shoulder of the tool of $25 \mathrm{~mm}$ and the area of $26.46 \mathrm{~mm}$ (center point of the plan).

Welding forces obtained by numerical simulation are approximately $10 \%$ higher than experimental forces, which means that the FSW process can be successfully simulated with FEM.

We can conclude that the largest maximum experimental measured values of the temperature are obtained in the first 16 points of the experimental plan where the dominant factor is the diameter of the shoulder of the tool of $28 \mathrm{~mm}$. In the central points of the experimental plan where the diameter of the shoulder is $26.46 \mathrm{~mm}$, small temperature values are obtained, where the average temperature at a distance of $7 \mathrm{~mm}$ from the joint line is $409.6^{\circ} \mathrm{C}$, and at a distance of $27 \mathrm{~mm}, 209.1^{\circ} \mathrm{C}$ in the upper zone. In the points of the experimental plan from 17 to 32, where the smaller diameter of the tool $25 \mathrm{~mm}$, a significantly lower temperature value is obtained. 
The numerical simulations also distinguish three temperature regions in which the temperature values are analogous to the experimental results.

A comparison of experimentally obtained temperature values with the values obtained by numerical simulation shows a relatively good agreement with the difference below $10 \%$. This allows the conclusion that heat generation and temperature distribution within the workpiece in the FSW process can be successfully simulated by FEM.

The deviation of numerical results from a physical experiment is conditioned by the DEFORM-3D characteristics. The software is based on the theory of small elasto-plastic deformations that, through a large number of steps, describe the large deformations that characterize the FSW process. High non-linearity is conditioned by the frequent occurrence of remeshing, i.e., transferring data from the old deformed mesh to a new undeformed mesh, which makes engineering tolerances of $10 \%$ possible.

Because of the complexity of the FSW process, which is accompanied by a large number of influencing parameters, this technology is a very wide research area. In this sense, our further research will focus on further theoretical analysis, experimental verification and numerical simulation of the FSW process, i.e., TES approach (T-Theory, E-Experiment, and S-Simulation).

Author Contributions: N.S. and M.V. developed the numerical model; N.S. experimental research; M.V. conceptualization; N.S. and M.V. discussed and analyzed the data.

Conflicts of Interest: The authors declare no conflict of interest.

\section{References}

1. Reynolds, A. Visualization of Material Flow in Autogenous Friction Stir Welds. Sci. Technol. Weld. Join. 2000, 5, 120-124. [CrossRef]

2. Dawes, C.; Thomas, W. Friction Stir Process Welds Aluminum Alloys. Weld. J. 1996, 75, 41-45.

3. Dialami, N.; Cervera, M.; Chiumenti, M. Effect of the tool tilt angle on the heat generation and the material flow in friction stir welding. Metals 2019, 9, 28. [CrossRef]

4. Hamilton, C.; Dymek, S.; Kopyscianski, M.; Weglowska, A.; Pietras, A. Numerically based phase transformation maps for dissimilar aluminum alloys joined by friction stir-welding. Metals 2018, 8, 324. [CrossRef]

5. Sibalic, N.; Vukcevic, M.; Janjic, M.; Savicevic, S. A study on friction stir welding of AlSi1MgMn aluminium alloy plates. Tech. Gaz. 2016, 23, 653-660.

6. Chen, C.; Kovacevic, R. Thermomechanical modeling and force analysis of friction stir welding by finite element method. J. Mech. Eng. Sci. 2004, 218, 509-519. [CrossRef]

7. Ulysse, P. Three-dimensional modeling of the friction stir-welding process. Int. J. Mach. Tools Manuf. 2002, 42, 1549-1557. [CrossRef]

8. Burford, D.; Tweedy, B.; Widener, C. Influence of shoulder configuration and geometric features on FSW track properties. In Proceedings of the 6th International Symposium on Friction Stir Welding, Saint Sauveur, QC, Canada, 10-13 October 2006.

9. Deng, $\mathrm{X}$; $\mathrm{Xu}, \mathrm{S}$. Two-dimensional finite element simulation of material flow in the friction stir welding process. J. Manuf. Process. 2004, 6, 125-133. [CrossRef]

10. Xu, S.; Deng, X.; Reynolds, A.; Seidel, U.T. Finite element simulation of material flow in FSW. Sci. Technol. Weld. Join. 2001, 6, 191-193. [CrossRef]

11. Lockwood, W.; Tomaz, B.; Reynolds, A. Mechanical response of friction stir welded AA2024: Experiment and modeling. Mater. Sci. Eng.: A 2002, 323, 348-353. [CrossRef]

12. Frigaard, O.; Grong, O.; Bjorneklett, B.; Midling, T.O. Modelling of the thermal and microstructure fields during friction stir welding of aluminium alloys. In Proceedings of the 1st International Symposium on Friction Stir Welding (1ISFSW), Thousand Oaks, CA, USA, 14-16 June 1999.

13. Bendzsak, G.; North, T.; Smith, C. An experimentally validated 3D model for friction stir welding. In Proceedings of the 2nd International Symposium on Friction Stir Welding (2ISFSW), Gothenburg, Sweden, 27-28 June 2000. 
14. Biswas, P.; Mandal, R.N. Effect of tool geometries on thermal history of FSW of AA1100. Weld. J. 2011, 90, 129-135.

15. Uyyuru, K.R.; Kailas, V.S. Numerical analysis of friction stir welding process. J. Mater. Eng. Perform. 2006, 15, 505-518. [CrossRef]

16. Chao, Y.; Xinhai, Q. Thermal and thermo-mechanical modeling of friction stir welding of aluminum alloy 6061-T6. J. Mater. Process. Manuf. Sci. 1998, 7, 215-233. [CrossRef]

17. Dong, P.; Lu, F.; Hong, J.; Cao, Z. Coupled thermomechanical analysis of friction stir welding process using simplified models. Sci. Technol. Weld. Join. 2001, 6, 281-287. [CrossRef]

18. Khandkar, M.; Khan, J. Thermal modelling of overlap FSW for Al-alloys. J. Mater. Process. Manuf. Sci. 2001, 10, 91-105.

19. North, H.T.; Bendzsak, J.G.; Smith, C. Material properties relevant to 3-D FSW modelling. In Proceedings of the 2nd International Symposium on Friction Stir Welding (2ISFSW), Gothenburg, Sweden, 27-28 June 2000.

20. Bjorneklett, I.B.; Grong, O.; Myhr, R.O.; Kluken, O.A. A process model for the heat-affected zone microstructure evolution in Al-Zn-Mg weldments. Metall. Mater. Trans. A 1999, 30, 2667-2677. [CrossRef]

21. Dialami, N.; Cervera, M.; Chiumenti, M. Numerical Modelling of Microstructure Evolution in Friction StirWelding (FSW). Metals 2018, 8, 183. [CrossRef]

22. Sibalic, N. Modeling and Simulation of the Process of Joining by Deformation-FSW. Ph.D. Thesis, University of Montenegro, Podgorica, Montenegro, 2010.

(C) 2019 by the authors. Licensee MDPI, Basel, Switzerland. This article is an open access article distributed under the terms and conditions of the Creative Commons Attribution (CC BY) license (http://creativecommons.org/licenses/by/4.0/). 